\title{
Forma e informação: um olhar de design sobre os artefatos informacionais do sistema de ônibus da cidade de São Paulo
}

Form and information: a design gaze upon the São Paulo's bus system's information artifacts

RODILHA, Bruno; Mestrando; Pontifícia Universidade Católica de São Paulo

bgrodilha@gmail.com

\section{Resumo}

A partir da sanção da Lei Federal 12.587/12 as informações passaram a figurar como direito essencial dos usuários de transporte coletivo e devendo ser apresentadas nos pontos de embarque e desembarque. Sendo assim, o presente artigo buscou documentar e analisar os principais artefatos informacionais que compõe o sistema de informação da rede de ônibus da cidade de São Paulo. Para tal, se realizou primeiramente uma revisão bibliográfica em design da informação e arquitetura e então por meio de incursões ao eixo Oeste-Centro-Leste da capital paulista o pesquisador buscou registrar fotograficamente tipologias de pontos e abrigos, para que a partir dessas imagens se desdobrassem análises projetuais e contextuais dos artefatos.

Palavras Chave: design da informação; wayfinding; transporte coletivo.

\begin{abstract}
Since the enactment of Federal Law $12.587 / 12$, the information becomes an essential right for the users of public transportation and its must be presented at the embarkation and disembarkation sites. Therefore, this article attempted to document and analyze the main urban artifacts of São Paulo's bus network's information system. For this, a bibliographical revision was first made in information design and architecture, and then incursions to photograph the bus stops typologies from the West-Center-East axis of the São Paulo city, for then develop a project and contextual analysis of the artifacts.
\end{abstract}

Keywords: information design; wayfinding; public transportation. 


\section{Introdução}

A informação permeia todas as esferas da vida humana nas suas diferentes formas e proporções, e o mesmo se dá no contexto do deslocamento urbano. O movimento pelas artérias da cidade exige equipamentos adequados tanto do ponto de vista físico quanto informacional, para que os serviços de transporte possam ser usufruídos em suas máximas potencialidades. Sendo assim, o papel do design da informação é prezar para que as relações informacionais sejam adequadas ao contexto do serviço, promovendo a melhor experiência possível aos usuários.

Com o advento da Lei Federal 12.587/12 a problemática da informação nos serviços de transporte coletivo ganhou suporte jurídico e passou a figurar como elemento primordial nos direitos dos usuários. No capítulo III, art. 14, inciso III, declara que os usuários de transporte coletivo têm o direito de serem informados nos pontos de embarque e desembarque de passageiros, de forma gratuita e acessível, sobre itinerários, horários, tarifas dos serviços e modos de interação com outros modais, sendo a exibição desse conteúdo de responsabilidade das operadoras. Por tanto, os equipamentos urbanos como pontos e abrigos, utilizados pelo serviço de ônibus, são os principais vetores informacionais dentro dos quesitos da lei, por entrarem em contato com usuário no embarque e desembarque.

Isto posto, o presente artigo buscou por meio de uma pesquisa de campo experienciar e documentar o estado dos artefatos informacionais do sistema de ônibus da cidade de São Paulo, a partir do eixo Oeste-Centro-Leste da cidade durante o ano de 2016. Com as imagens coletadas o pesquisador conduziu análises para cada tipologia identificada, a fim de tecer uma crítica sobre os projetos implantados e assim expor a situação frequentemente encontrada pelos usuários do sistema de ônibus nas ruas paulistanas.

\section{Quadro referencial teórico}

Sendo o processo de deslocamento uma dinâmica essencial para o funcionamento da cidade ocidental, como é posto por Benevolo (1983), é importante compreender os vetores informacionais que influenciam a locomoção de pessoas e mercadorias pela malha urbana. Utilizando o pensamento de Kevin Lynch (2010), compreende-se a organização da urbe a partir de sua visualidade, o que leva em conta a participação dos habitantes no processo de significação do ambiente, a maneira como navegam e se orientam, compondo um vocabulário visual. Com isso, todos as dinâmicas de transporte e movimento pelas artérias da urbe se dão graças às imagens construídas do ambiente, por meio de processos interpretativos e perceptivos das relações entre imagens mentais e signos informacionais/arquitetônicos.

No processo de orientação, o elo estratégico é a imagem do meio ambiente, a imagem mental generalizada do mundo exterior que o indivíduo retém. Esta imagem é o produto da percepção imediata e da memória da experiência passada e ela está habituada a interpretar informações e a comandar ações. (LYNCH, 2010, p. 14)

Sendo assim, as imagens integram parte essencial na efetivação dos deslocamentos urbanos, pois por meio dessas é que os habitantes são capazes de se situar em meio a malha urbana e estabelecer sua navegação. Isto posto, pode-se compreender que o mobiliário urbano carrega em si uma potencialidade informacional, capaz de contribuir na orientação espacial das pessoas.

Com a intenção de analisar os elementos imagéticos citadinos, Lynch (2010) esquematizou três características de uma imagem eficiente no meio urbano: identidade, estrutura e significado. 
Assim, uma imagem deve ter como componente primário a ideia de identidade, o que seria a capacidade de diferenciação do objeto em meio aos muitos outros que se encontram no campo visual. Para isso, é necessário que este estabeleça uma relação indireta com o indivíduo por meio de sua particularidade, destacando-se no ambiente. Como caráter complementar ao primeiro, a imagem deve estabelecer, enquanto se particulariza, uma relação estrutural com o espaço e os objetos que a cercam, mantendo a coerência espacial por meio de uma relação direta. E, por fim, unindo as características da imagem, temos o significado como consequência da relação direta entre indivíduo e objeto, atribuindo-Ihe um conceito e/ou função perante à sua experiência.

No contexto do transporte coletivo urbano, os pontos propostos por Kevin Lynch (2010) materializam-se no projeto de equipamentos como sinalização gráfica e sonora, abrigos e pontos de parada. O principal objetivo informacional desses recursos projetuais deve ser estabelecer em meio ao ambiente referenciais para a navegação citadina e para o uso do serviço de transporte.

Rüetschi e Timpf (2005) propõem para o projeto informacional de uma rede de transporte coletivo que se atenha as etapas da viagem: pre-trip, on-trip, end-trip. Essas se dão progressivamente conforme o avanço dos usuários no processo de deslocamento. A primeira fase da viagem, pre-trip, é composta pelas ações prévias ao ingresso do usuário no sistema de transporte, como o planejamento da viagem, o deslocamento até um ponto de acesso (terminais, estações e paradas) e sua entrada no sistema. A partir do momento em que o usuário se encontra em movimento pela rede, tem-se o on-trip, caracterizado pelo movimento do usuário dentro da rede conforme o trajeto escolhido, entrando em contato com paradas e interligações (com outros modais e outras linhas) ao longo de seu caminho. Qualquer mudança de modal ou linha durante a viagem se enquadra no momento de on-trip, pois faz parte do processo de deslocamento do ponto de partida até o destino, o que aponta para uma preocupação por parte da modelagem das redes informacionais na resposta às demandas quanto ao acompanhamento do usuário dentro da rede, situando-o geograficamente e sistemicamente durante todo esse período. Por fim, como última fase da viagem, end-trip, o usuário alcança o seu destino e deixa o sistema, levando consigo um aprendizado quanto ao caminho que se sucedeu.

Figura 1 - Etapas da viagem por Rüetschi e Timpf (2005)

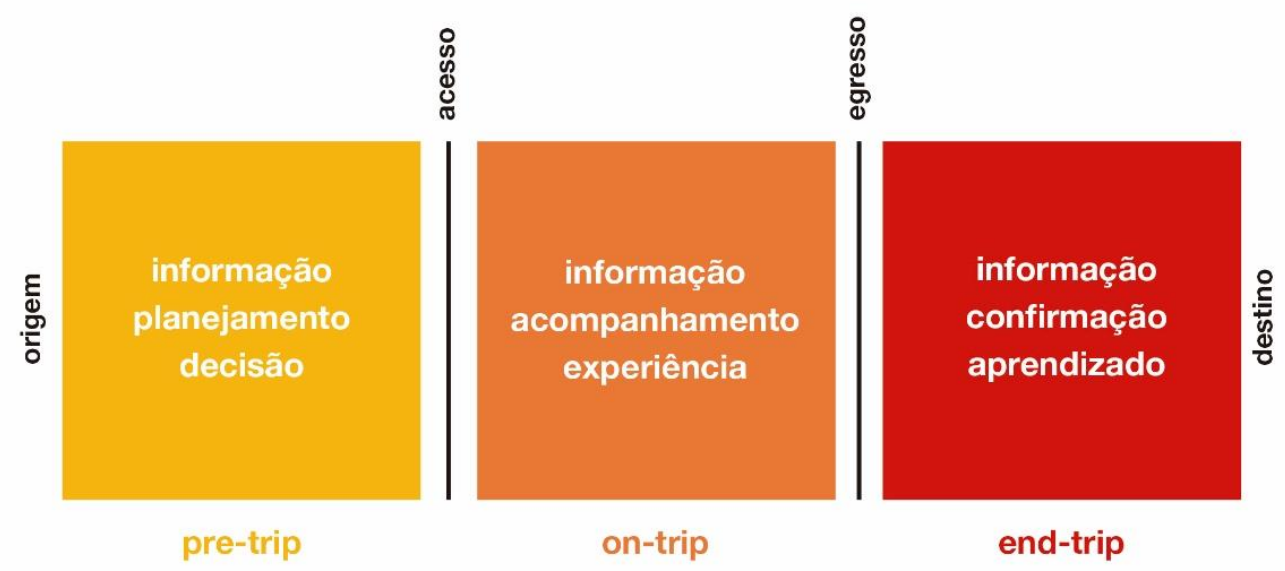

Fonte: Imagem do autor (2016) 
Isto posto, os artefatos informacionais devem compreender as diferentes necessidades informacionais ao longo das três etapas. Para o pre-trip, contamos com pontos de parada e abrigos, que devem apresentar informações necessárias para o processo de escolha (como as linhas, valor das passagens e integrações possíveis), além de cumprir o seu papel quanto marco navegacional no ambiente urbano. Os equipamentos dispostos no on-trip devem possibilitar o acompanhamento da decisão tomada anteriormente. Ou seja, capacitar o usuário a se situar dentro do sistema e da malha urbana. Com o egresso do sistema de transporte, end-trip, o usuário ainda requer apoio de artefatos informacionais capazes de confirmar a o seu destino, consolidando sua experiência.

Bovy e Stern (1990) quanto a relação entre o uso do transporte coletivo e o processo de aprendizado do usuário. Para os autores o deslocamento por modal coletivo inerentemente traz consigo experiências de aquisição de conhecimento sobre os aspectos práticos do sistema de transporte e sobre a própria cidade. $O$ aprendizado é resultado do conjunto de experiências que o usuário passa ao entrar em contato com o serviço de transporte, construindo conhecimento sobre o sistema, variando em diversos graus de acordo com a frequência e a profundidade da convivência com este sistema.

De acordo com Bovy e Stern (1990) o aprendizado do usuário se desenvolve ao longo de toda a viagem e se consolida quando o deslocamento é concluído (end-trip). O usuário adquire informações e experiências gradualmente conforme utiliza o serviço de transporte. Por tanto, para os autores, o projeto de um sistema de informação para transporte coletivo deve ter como objetivo maior possibilitar o aprendizado espacial (Spatial Knowledge), visando a autonomia das pessoas por meio da simplificação e enriquecimento da experiência de uso.

Os artefatos táteis e gráficos tonam tangíveis as demandas informacionais, estabelecendo contato direto com o usuário e o apoiando durante sua viagem. Nesse sentido, a reflexão quanto ao exercício projetual desses objetos deve levar em conta os seus papéis em meio a um sistema, e assim, formar relações objeto-usuário, objeto-objeto e objeto-ambiente de maneira adequada.

Para Calori e Vanden-Eynden (2007) o design dos objetos informacionais não deve limitarse aos recursos projetuais presentes na peça final, já que a modelagem de um sistema de comunicação transpassa diferentes camadas de conhecimento e todas elas devem estar configuradas no objeto. Sendo assim, os autores desenvolveram uma metodologia baseada em três pilares de desenvolvimento para a execução de um projeto de wayfinding, iniciando-se com a preparação e a articulação das informações (Information System), passando pela elaboração gráfica/visual (Graphic System) e finalizando com a confecção dos suportes (Hardware System).

In this respect, the information content system can be thought of as the software of a sign program - you can't see it or touch it but the sign program wouldn't be functional without it. (CALORI; VANDEN-EYNDEN, 2007, p. 83)

A base para qualquer tipo de sistema informacional (visual, sonoro ou tátil) sempre será a informação em si e, como é posto por Calori e Vanden-Eynden, a interpretação dos dados e o momento no espaço/tempo em que esses serão apresentados ao usuário é a etapa mais importante no projeto, uma vez que envolve a elucidação das demandas informacionais, a articulação dos dados brutos e, por fim, a contextualização quanto aos processos de tomada de decisão e às etapas da navegação, produzindo, então, as mensagens que serão transmitidas aos usuários.

O passo subsequente ao projeto diz respeito à esfera comunicacional (Graphic System), buscando interpretar visualmente as mensagens articuladas anteriormente a partir do 
desenvolvimento de um vocabulário gráfico que dialogue adequadamente com a função estabelecida e o contexto objetivo e subjetivo do usuário. Nesse sentido, todas as ferramentas visuais a serem dispostas em um artefato informacional devem ser frutos de um exercício de reflexão e pesquisa quanto à sua efetividade, como pontes de comunicação.

A esfera dos suportes (Hardware System) compõe-se das estruturas táteis, formas, volumes e luzes, utilizados como base para a transmissão de mensagens por meio do sistema gráfico (visual). Sua função deve abarcar, além do sustentáculo visual, um objetivo próprio na esfera comunicacional, circunscrevendo-se no ambiente de maneira a estabelecer canais de comunicação adicionais através de recursos táteis e visuais (além de tela e impressão). Calori e Vanden-Eynden (2007) estabelecem modelos para a exposição de informações no espaço com base no suporte montado (mounting), que se apresenta em quatro formas diferentes, adaptáveis a situações diversas, tendo como fatores a possibilidade de instalação (apoios como paredes, teto ou o solo) e a visibilidade. Logo, o projeto do sistema de suportes deve levar em conta a funcionalidade do objeto em relação ao meio no qual este será fixado, dialogando com as possibilidades naturais que Ihe são apresentadas a fim de reduzir o custo de instalação (quando necessário) e atender às necessidades informacionais adequadamente. Os equipamentos que se prendem ao chão (groundmounted), como pirulitos e totens, se mostram uma alternativa versátil para a aplicação tanto em lugares abertos quanto fechados, por se tratar de um suporte de fácil instalação, porém acabam por ocupar espaço de circulação das pessoas. Já os aparatos suspensos (suspendend), os projetados perpendicularmente (flag-mounted) e os painéis fixos (flat wall-mounted) livram o chão, porém necessitam de estruturas construídas que os apoiem, sendo, portanto, uma alternativa ligeiramente mais restrita em sua implementação, tendo em vista o ambiente urbano (aberto).

Por tanto, o pensamento projetual quanto aos suportes, portanto, deve estar alinhado às diretrizes estruturais do processo de navegação e prezar por um diálogo ativo entre artefato tátil e artefato visual, formando uma rede que seja capaz de circunscrever-se no ambiente aproveitandose das duas características em prol da comunicação.

\section{Método}

A pesquisa aqui apresentada se desenvolveu em dois momentos, sendo o primeiro de caráter observacional-fotográfico e o segundo voltado para análise do material coletado em campo. A etapa inicial pautou-se na experiência empírica do autor, captando o funcionamento das linhas do ponto de vista do usuário médio que por vezes utiliza-se do transporte coletivo rodoviário junto a outros modais (trem, metrô, carro, bicicleta e a pé). As imagens utilizadas na pesquisa foram capturadas no eixo Oeste-Centro-Leste da cidade de São Paulo no ano de 2016 e apresentam diferentes aparelhos informacionais que compõe o sistema de ônibus da cidade.

Quanto as análises imagéticas, buscou-se interpretar o funcionamento dos equipamentos urbanos com base na bibliografia especializada, compreendendo seus aspectos funcionais, estruturais e informacionais, dentro do contexto paulistano. As imagens foram divididas em dois grupos, com base em suas tipologias: pontos e abrigos. Tal categorização acaba por refletir, além dos aspectos projetuais dos equipamentos, as interações informacionais objeto-usuário, objetoobjeto e objeto-ambiente.

A abordagem utilizada centrou-se na literatura de design da informação, dando uma visão sistêmica dos artefatos dentro de uma dinâmica navegacional e um tratamento projetual para 
aprofundar o olhar sobre os objetos em si. Além disso, as análises tiveram como respaldo o pensamento de Kevin Lynch (2010) com o propósito de contextualizar as relações informacionais no ambiente urbano.

\section{Análises}

\subsection{Pontos}

Pode-se entender o ponto como o artefato informacional mais primal dentro de um sistema de ônibus, tendo como principal objetivo identificar os locais de ingresso e egresso de uma rede de transporte coletivo. Porém, como discutido por Rüetschi e Timpf (2005) tais artefatos devem apresentar informações (visuais e táteis) capazes de dar suporte ao planejamento da viagem, bem como trazer maneiras de confirmar e situar a localização do usuário na urbe e na rede, após sua viagem.

Os pontos encontrados durante a pesquisa eram compostos primariamente por uma haste fixada de maneira perpendicular ao solo, que Calori e Vanden-Eynden (2007) categorizam como ground-mounted, mas além disso algumas tipologias contam com outros elementos construtivos, e a partir desses foi feitam a seguinte categorização: hastes; pirulitos; totens; painéis.

As hastes são compostas por um elemento único fincado no solo. Sendo majoritariamente construído em madeira com uma aplicação de tinta colorida com o objetivo de destacar o marco em meio ao ambiente urbano. Este modelo de equipamento remonta aos primeiros objetos informacionais instalados pela CMTC ainda nos anos 1950, tendo passado por pequenas manutenções (retoque e mudanças na pintura) sem ter passado por maiores alterações. Os pontos hastes apresentam destaque moderado na paisagem urbana devido à cor aplicada sobre a madeira, porém os próprios aspectos construtivos do suporte (haste vertical de madeira) não possibilitam, de maneira viável, a instalação de qualquer tipo de material gráfico para informar o usuário quanto ao serviço, ou elemento visual que amarre o artefato ao sistema de ônibus consistentemente. Essas características podem gerar uma sensação de insegurança no usuário fazendo com que haja a dependência da informação verbal para que as informações cheguem até a pessoa.

Figura 2 - Ponto haste

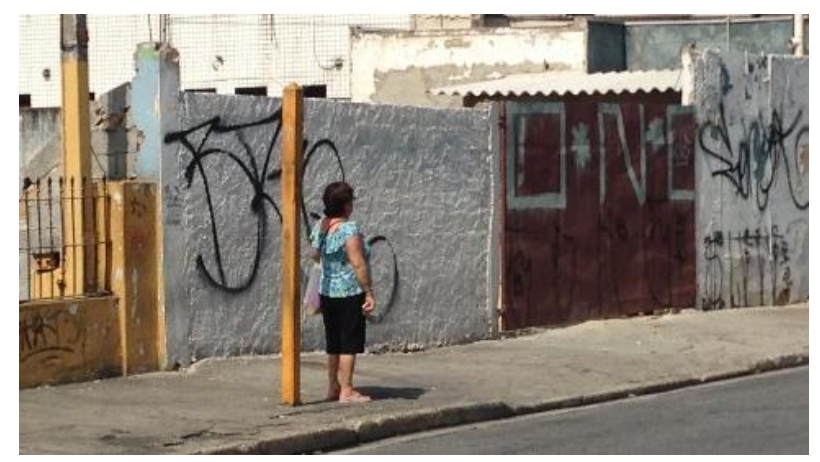

Fonte: Imagem do autor (2016)

Os pontos pirulitos, diferentemente do primeiro modelo apresentado, contem, além da estrutura vertical, uma placa em seu topo, que tem como objetivo expor informações gráficas. Analisando o suporte, com base nos conceitos apresentados por Calori e Vanden-Eynden (2007), 
observa-se que a forma de exibição das informações nesse suporte apresenta ruídos, pois requerem maior atenção para leitura (dias de funcionamento, nome e número das linhas) localizam-se acima do nível dos olhos (eye-level), tornando dificultosa sua visualização.

Figura 3 - Ponto pirulito

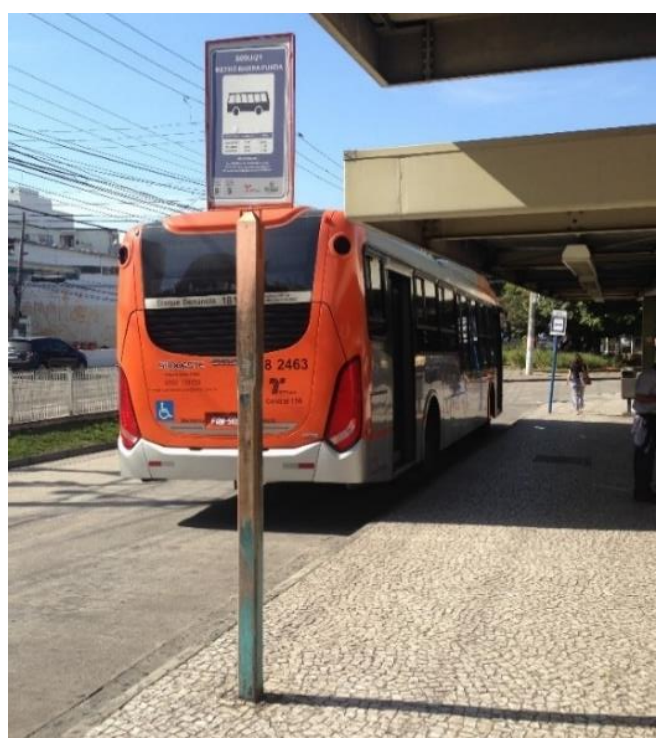

Fonte: Imagem do autor (2016)

Os pontos totens foram encontrados em duas formas diferentes: o prisma metálico de três faces e o mais recente totem de duas faces instalados em 2015. O primeiro tipo denota resquícios do projeto desenvolvido por Cauduro e Martino nos anos 1970 em seus aspectos construtivos, porém os esforços informacionais presentes nos desenhos originais não se encontram mais nos exemplares avistados durante a pesquisa. Estes tipos apresentam pinturas e aplicações não padronizadas, podendo ser encontrados em cor azul com o logo da SPTrans aplicado ou em cor metálica crua do material com um pictograma de ônibus fixado por meio de adesivo. Tais características geram inconsistência entre os objetos da mesma tipologia, produzindo entropia visual ao não se conectar a rede. 
Figura 4 - Ponto totem de três faces

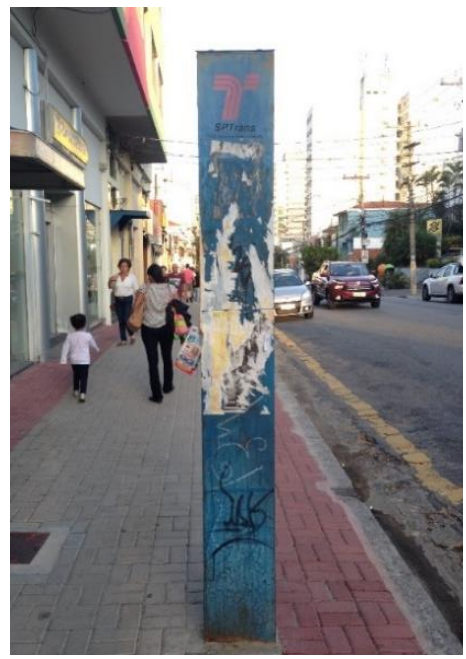

Fonte: Imagem do autor (2016)

Quanto aos totens de duas faces, pertencentes ao mais recente projeto de mobiliário urbano da capital paulista, é perceptível que a coloração (marrom, prata, preto e cinza) não os destaca no ambiente visualmente entrópico da cidade, tornando-os marcos navegacionais pouco eficientes. $O$ contraste visual da peça fica a cargo do pictograma colorido (amarelo sobre marrom, azul sobre prata, azul sobre preto e azul sobre cinza) aplicado com adesivo ou acrílico nas duas faces, criando um único ponto de tensão visual em todo o artefato. Tal feito cria uma identidade para as peças e as une por familiaridade, porém não as faz mais perceptíveis no ambiente urbano por conta de sua paleta cromática. As informações impressas encontram apoio adequado na estrutura do totem, pois as duas superfícies são consideravelmente largas possibilitando a aplicação de material informativo. No entanto, o que pôde ser constatado durante a pesquisa de campo é que poucos exemplares estavam devidamente equipados com informativos, ou quando estavam, muitos encontravam-se com barreiras físicas para a sua visualização.

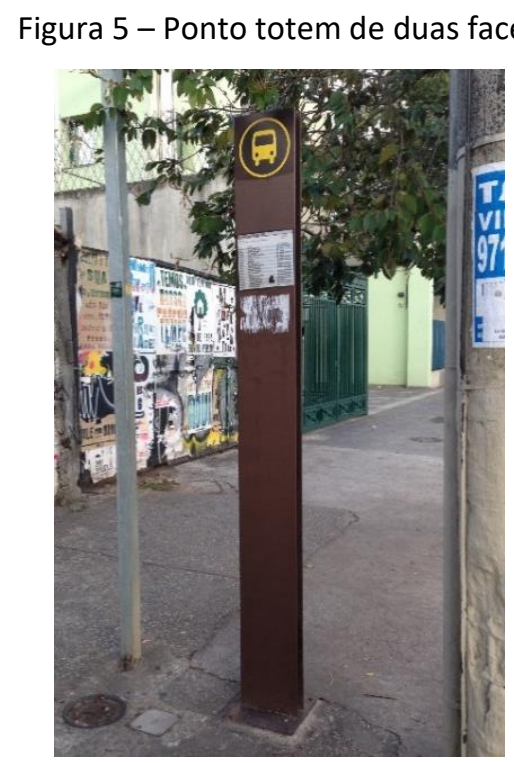

Fonte: Imagem do autor (2016) 
Os pontos painéis contam com poucos exemplares nas regiões observadas pela pesquisa, e estes são construídos a partir de duas hastes, erguendo um painel central no qual se apresentam informações. Embora beneficie a apresentação de informações complexas, podem acabar obstruindo a passagem de pedestres nas calçadas devido a área que ocupa. Quanto a experiência apreendida em campo, notou-se que essa tipologia de ponto era a que mais encontrava-se degradada, aparentando não ter passado por nenhuma manutenção desde sua instalação.

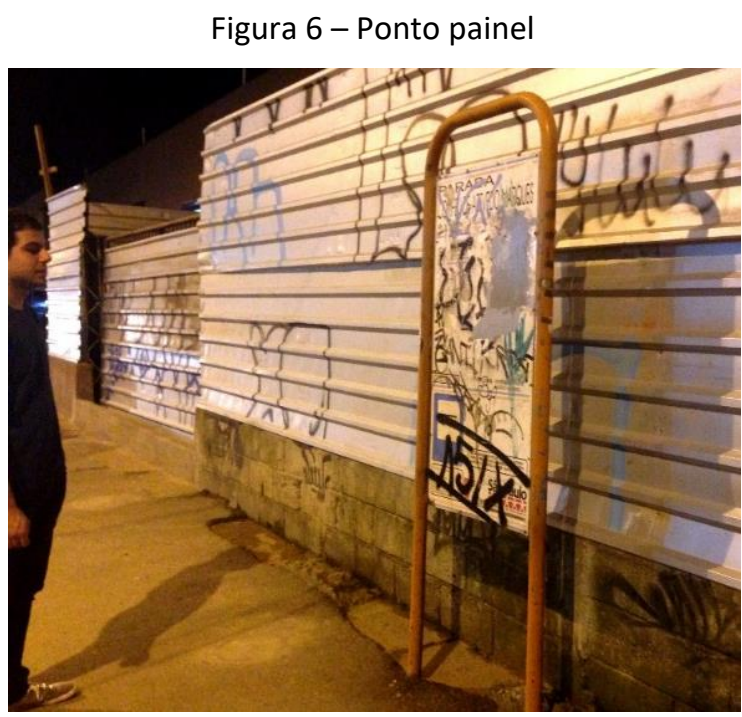

Fonte: Imagem do autor (2016)

Assim, é possível notar a convivência de diferentes tipologias de pontos evidenciam a inconsistência da rede informacional do sistema de ônibus da cidade. Além disso, cada um dos modelos apresenta soluções extremamente diferentes entre si quanto às maneiras de atender às demandas informacionais dos usuários, predominando as soluções táteis e ambientais, não se atentando as esferas gráficas que poderiam potencializar o processo comunicacional objeto-usuário.

\subsection{Abrigos}

O abrigo tem a como função primária a indicação dos locais de acesso e egresso do sistema, assim como os pontos, mas além disso provêm conforto aos usuários enquanto aguardam para adentrar a rede de transporte coletivo. Sendo assim, sua característica construtiva, no geral, é uma cobertura e duas colunas, que lhe servem de sustentáculo. As análises são se focarão nas questões arquitetônicas dos artefatos, mas sim em como esses se colocam dentro das dinâmicas informacionais.

Registrou-se a presença de abrigos primitivos de concreto, telha e madeira na região central da cidade, que é um projeto histórico que remonta aos primeiros abrigos instalados na cidade pela CMTC. Este artefato, apresenta uma cobertura simples capaz de proteger os usuários da luz solar e de chuvas perpendiculares com visível eficiência. Porém, o desenho do abrigo não compreende nenhum suporte para a instalação de informativos, contando somente com a superfície das duas colunas de sustentação para a aplicação de material gráfico. 


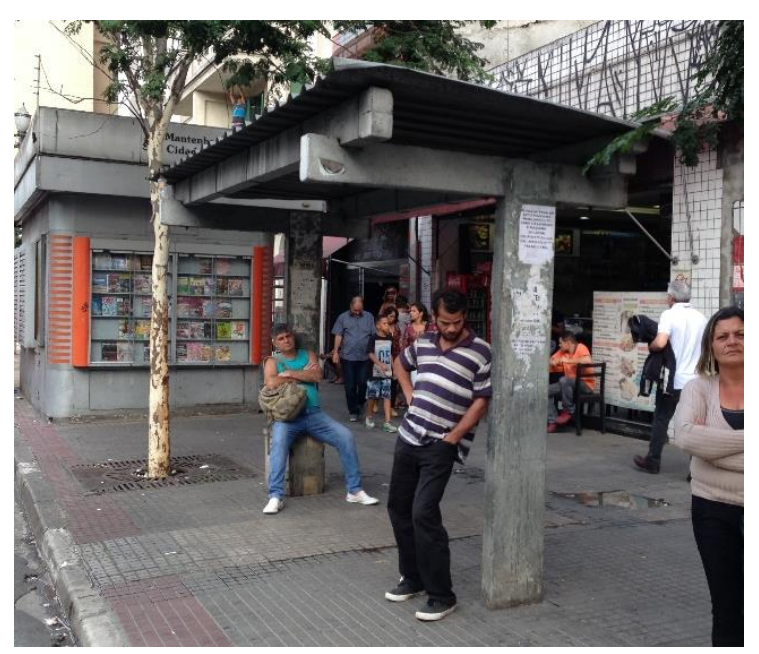

Fonte: Imagem do autor (2016)

O abrigo curvo, encontrado em uso em algumas avenidas da região Oeste e no centro da cidade, é um projeto que apresenta esforços para atender as demandas informacionais, por meio de espaços destinados a fixação de materiais informativos e a apresentação dos nomes das paradas. $\mathrm{O}$ adesivo fixado na região superior da estrutura curva, que nomeia a parada, apresenta ruídos visuais por conta do pouco contraste entre a cor das letras e a pintura da coluna metálica. Essa dificuldade de legibilidade tornando a leitura a longas distâncias (como a partir do ônibus em movimento) quase inviável. Quanto aos espaços reservados a informativos oficiais do sistema de transporte, nota-se que a localização deles pode vir a interferir na leitura, já que se encontram atrás dos bancos e apoios onde os usuários se acomodam, obstruindo a visualização dos materiais gráficos.

Figura 8 - Abrigo curvo

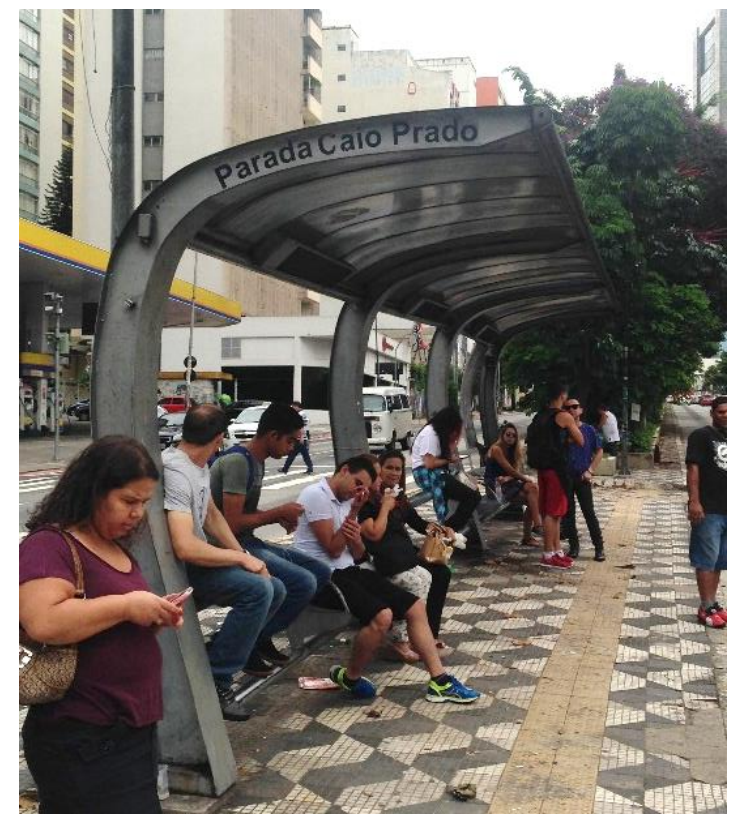

Fonte: Imagem do autor (2016) 
Durante a pesquisa de campo foi encontrado um tipo de abrigo, instalado em frente ao Conjunto Nacional (Av. Paulista), que não se apresentam em nenhuma outra localidade compreendida no eixo da pesquisa de campo, evidenciando a multiplicidade de tipologias de pontos e abrigos fixados pela cidade de São Paulo. Esse objeto de design preocupa-se em atender às necessidades físicas dos usuários, contando com bancos e apoios suficientes, além de uma cobertura maior destinada à proteção contra chuvas perpendiculares e à exposição solar direta. Porém, partindo para sua função informacional, notou-se que, no grupo de quatro abrigos instalados, somente um deles apresenta um painel com informações. Isso se mostra insuficiente, visto que, em uma parada movimentada, é necessário que se tenha um número maior de pontos de contato dos usuários com os dados a respeito do sistema de transporte.

Figura 9 - Abrigo do Conjunto Nacional (Av. Paulista)

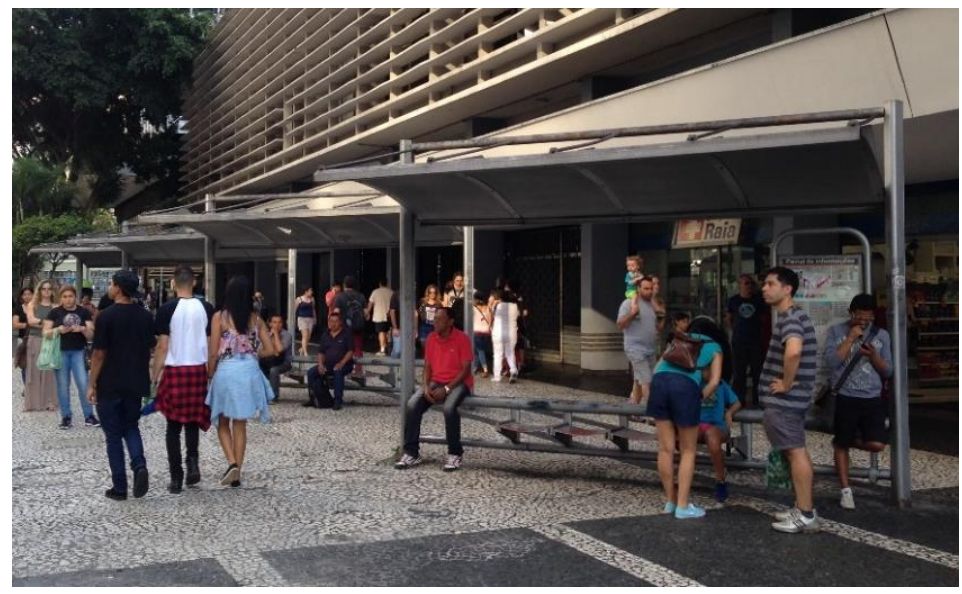

Fonte: Imagem do autor (2016)

O mais recente projeto de mobiliário urbano na cidade de São Paulo é resultado do projeto do designer Índio da Costa e teve a sua instalação por meio de um convênio entre a iniciativa privada e a prefeitura, sendo concluída no ano de 2015. O projeto conta com quatro desenhos de abrigos diferentes, que, de acordo com o designer responsável, foram concebidos tendo em mente a sua adequação as diferentes paisagens da cidade. Assim, a pesquisa analisou cada um dos tipos individualmente, para compreender suas particularidades projetuais e suas relações objeto-espaço.

O primeiro modelo a ser analisado é o "Caos Estruturado", construído a partir de colunas metálicas dispostas em diagonal que sustentam o abrigo e servem de fixação para um painel de vidro. Esse modelo específico foi, dentre os quatro modelos mais recentes, o mais encontrado pelas ruas paulistanas. No que diz respeito às suas instâncias informacionais, a grande superfície de vidro não é utilizada para aplicar qualquer material informativo, restando somente as faces dos totens (sempre instalados em conjunto com o abrigo) para receber informação gráfica. O projeto dessa tipologia não levou em conta a individualidade, apresentada por Lynch (2010), essencial para que se crie um marco navegacional eficiente, pois sua pintura marrom não destaca o artefato no meio urbano, criando tensão suficiente no olhar dos habitantes capaz de contrastar com o ambiente. 
Figura 10 - Abrigo “Caos Estruturado”

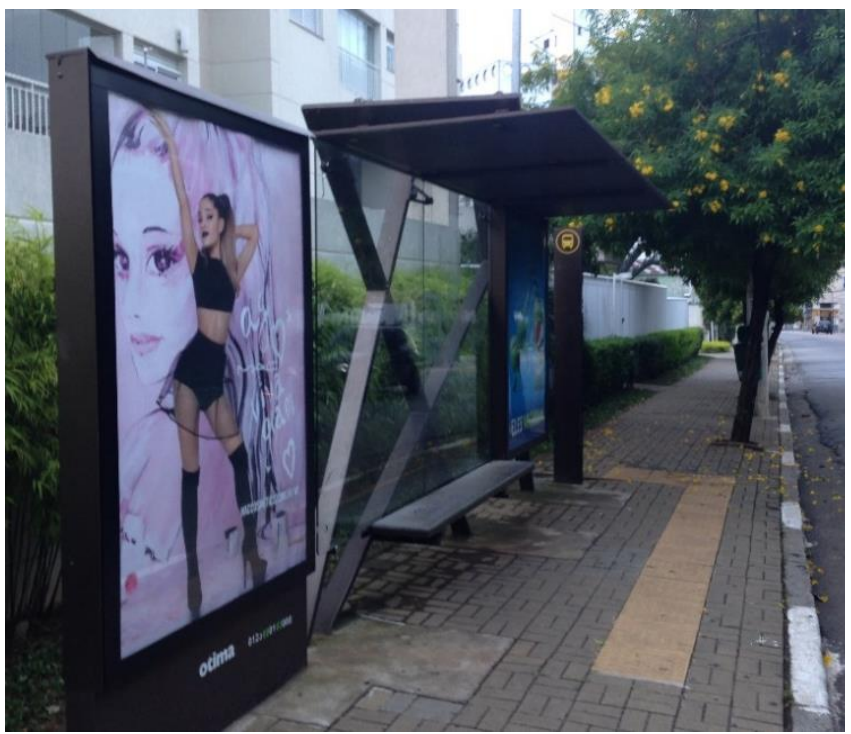

Fonte: Imagem do autor (2016)

O modelo "Brutalista" foi encontrado em menor número pela pesquisa de campo, estando presente somente em alguns trechos da Marginal Tietê. A tipologia possui linhas mais robustas e conta com uma estrutura de concreto pré-moldado e acabamento em cimento queimado. $O$ aspecto visual do artefato confere robustez e rigidez ao desenho, mas dialogando ativamente com o modelo anterior tanto em seu traçado quanto pela presença dos painéis de vidro (marca registrada do projeto como um todo). O abrigo "Brutalista" se mostra ainda menos propício para a aplicação de informações, pois sua estrutura possui cortes e acabamentos que impedem a fixação de impressos adesivos, reduzindo às faces do totem a possibilidade de colocação de informativos.

Figura 11 - Abrigo "Brutalista"

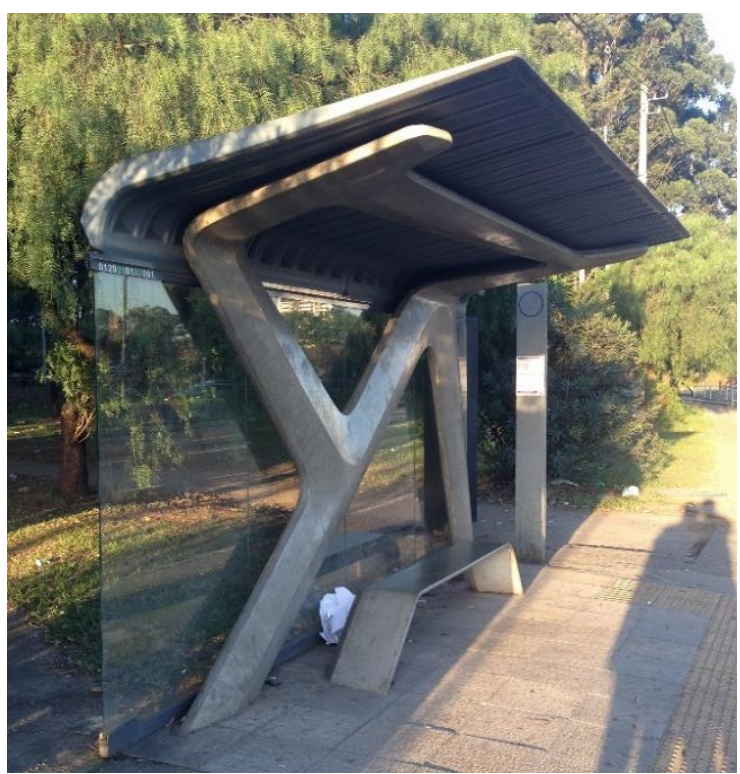

Fonte: Imagem do autor (2016) 
A terceira tipologia é a "Minimalista", que possui um desenho que muito se assemelha ao desenho das paradas de ônibus parisienses, por estruturar-se em linhas simples que privilegiam os painéis de vidro. De acordo com Índio da Costa, o objetivo é interferir o mínimo possível na visualidade da cidade, porém essa abordagem acaba por tornar a peça ineficaz enquanto marco navegacional, dificultando os processos perceptivos dos usuários durante o acompanhamento da viagem ou no próprio planejamento, pois muitas paradas podem passar despercebidas. Assim como nos dois modelos já tratados, existem problemas para a aplicação de material gráfico, já que há somente as duas colunas metálicas de sustentação para a fixação de informações (em nenhum dos exemplares encontrados pela pesquisa havia qualquer material aplicado).

Figura 12 - Abrigo "Minimalista”

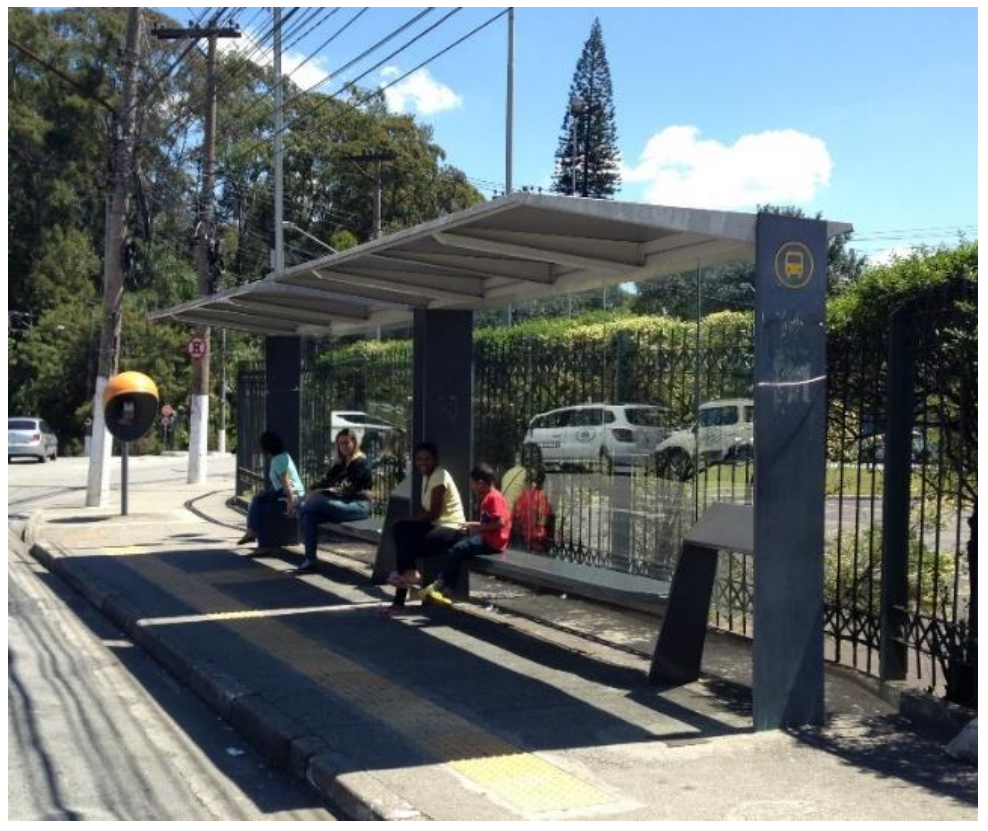

Fonte: Imagem do autor (2016)

Por fim, o modelo "High-Tech", instalado nas principais avenidas comerciais do centro novo da cidade, traz o mesmo problema estrutural para a acomodação de conteúdo informativo que os três anteriores, pois novamente exaltam-se os painéis de vidro (e a publicidade) em detrimento de superfícies nas quais possam ser aplicados materiais informativos. Esse tipo conta com um acabamento de aço escovado, dando um aspecto moderno, que pode torná-lo ligeiramente destacado da cena urbana, porém a falta de sinais gráficos para aprofundar esse contraste faz com que a peça permaneça com pouco apelo visual para quem passa a distância. O modelo "High-Tech" é o único na cidade que conta com displays eletrônicos grandes (nas mesmas dimensões dos displays publicitários) que poderiam vir a ser utilizados, mesmo que com intervalos, para a exibição de informações, porém em todos os casos encontrados por esta pesquisa notou-se o uso exclusivo desses equipamentos para a exploração publicitária. 
Figura 13 - Abrigo "High-Tech"

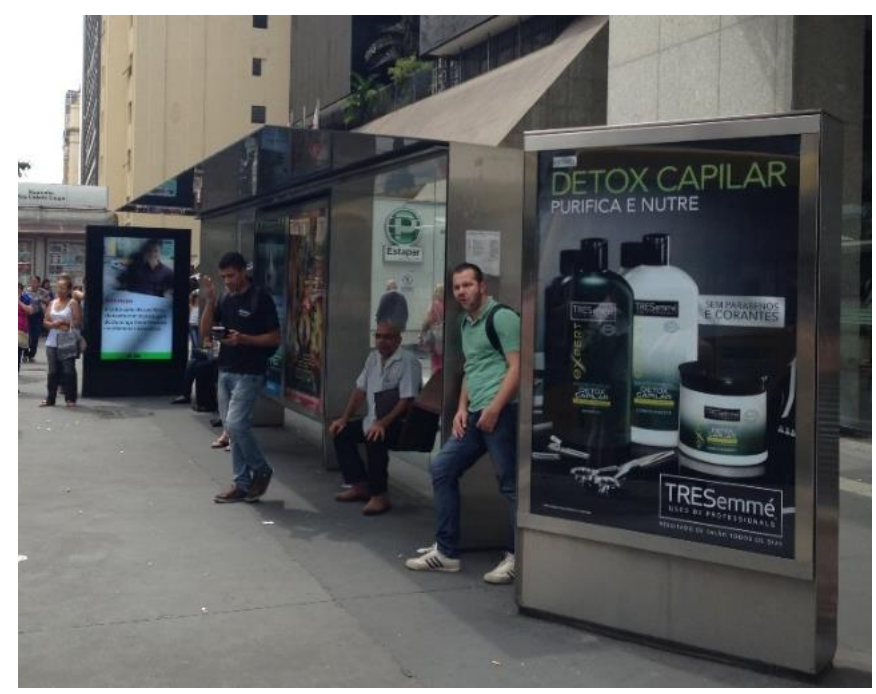

Fonte: Imagem do autor (2016)

\section{Considerações finais}

Compreendendo a importância da informação para o bom funcionamento dos serviços de transporte coletivo e sendo essa assegurada legalmente pela Lei Federal 12.587/12, vê-se por meio da documentação fotográfica e das análises dos equipamentos informacionais que o atual estado do sistema informacional do serviço de ônibus não compreende adequadamente as necessidades dos usuários. Sendo os principais aspectos detectados durante a pesquisa: a multiplicidade de tipologias de pontos e abrigos pelas ruas visitadas (eixo Oeste-Centro-Leste); a falta de consistência formal e comunicacional; e a ineficiência dos projetos de mobiliário urbano implementados (no que diz respeito às relações informacionais).

Os problemas projetuais encontrados têm reflexo direto na compreensão do funcionamento da rede de ônibus e, consequentemente, interfere negativamente na experiência dos usuários, seja pela ausência de informações nos pontos de acesso, seja pelos ruídos causados pela falta de manutenção. Os artefatos observados apresentam falhas projetuais no que diz respeito à adequação ao contexto urbano e quanto a própria função dos objetos. Pois não se inserem no cenário adequadamente e tampouco respondem internamente as demandas informacionais de cada etapa da viagem.

Por meio da pesquisa de campo foi possível constatar que a maioria dos pontos e abrigos observados não apresentavam material informativo oficial da SPTrans a respeitos da rede de ônibus, ou quando possuíam o informe, este encontrava-se em más condições de conservação, comprometendo a legibilidade. Apesar desse fato não se inserir diretamente na problemática gráfica da pesquisa, serve como informação adicional na documentação do atual estado do sistema informacional, que se encontra desamparado no que diz respeito à sua conservação e manutenção.

Portanto, foi possível concluir que o sistema de informação da rede de transporte coletivo urbano da cidade de São Paulo não está em conformidade com os preceitos legais, bem como não atende aos princípios projetuais e conceituais adotados por esta pesquisa. 


\section{Referências}

BENEVOLO, Leonardo. História da cidade. São Paulo: Perspectiva, 1983

BONSIEPE, Gui. Design, cultura e sociedade. São Paulo: Blucher, 2011. . Teoria y practica del Diseño Industrial. Barcelona: Gustavo Gilli, 1975.

BOVY, Piet H. L.; STERN, Eliahu. Route Choice: Wayfinding in Transport Networks. Dordrecht: Kluwer Academic Publishers, 1990.

CALORI, Chris; VANDEN-EYNDEN, David. Signage and Wayfinding Design. New Jersey: Wiley, 2007. CARDOSO, Rafael. Design para um mundo complexo. São Paulo: Cosac Naify, 2012.

CAUDURO, João Carlos; MARTINO, Ludovico. Plano Diretor do Sistema de Comunicação Visual dos Transportes Públicos. São Paulo, 1974.

HOMEM DE MELO, Chico. Interesses privados e políticos condicionam o design público de São Paulo. In: Projeto DESIGN, n. 287, FAU-USP, 2004, p. 86-89.

LYNCH, Kevin. A imagem da Cidade. São Paulo: Martins Fontes, 2010.

RÜETSCHI, Urs-Jakob; TIMPF, Sabine. Modelling wayfinding in public transport: network space and scene space. In: Spatial Cognition IV. Zurique, 2005. p. 21-44. 